\title{
Einleitung zum ersten Band der Ersten Abteilung
}

Der vorliegende Band 1 der Ersten Abteilung der MEGA enthält die überlieferten Werke, Artikel und literarischen Versuche von Karl Marx, die bis März 1843 entstanden. Zusammen mit den im Band 1 der Dritten Abteilung wiedergegebenen Briefen und den im Band 1 der Vierten Abteilung enthaltenen Exzerpten beleuchten die Dokumente die Anfänge der politischen und philosophischen Entwicklung von Karl Marx, seine eigenständige Entwicklung als Junghegelianer sowie die Herausbildung und Formung seiner revolutionär-demokratischen Anschauungen.

Die in den Band aufgenommenen Arbeiten stammen aus einer Zeit, in der Marx das Gymnasium in Trier verließ, um in Bonn und Berlin zunächst Jura, später Philosophie zu studieren. In diesen Studienjahren begann Marx um einen eigenen politischen und philosophischen Standpunkt zu ringen. Das Ergebnis war das Bekenntnis zur Hegelschen Philosophie, der Anschluß an den Kreis der Junghegelianer um Bruno Bauer sowie die ersten Versuche schöpferischer wissenschaftlicher Arbeit. Daneben versuchte sich Marx als Poet. Am Ende seiner Studienjahre lagen die Beschäftigung mit der Philosophie Epikurs, mannigfaltige Pläne von wissenschaftlichen Publikationen, mit denen Marx an den philosophischen Auseinandersetzungen seiner Zeit teilnehmen wollte, und die Ausarbeitung der Dissertation. Mit dieser Arbeit deutete der Junghegelianer Marx bereits einen selbständigen Weg seiner weltanschaulichen Entwicklung an. Nach mehreren Monaten enger Zusammenarbeit mit Bruno Bauer, deren Ergebnis eine gemeinsame Publikation über Hegels Religionsphilosophie sein sollte, begann Marx Anfang 1842 seine publizistische Tätigkeit. Die Mitarbeit an der "Rheinischen Zeitung", vor allem der Eintritt in die Redaktion einer 
Tageszeitung, wurden für die Herausbildung und Entwicklung der revolutionär-demokratischen Ansichten von Marx sehr bedeutungsvoll, sie beeinflußten in starkem Maße sein weiteres theoretisches Schaffen, die Entwicklung seiner Weltanschauung und bereiteten seinen Übergang zum Materialismus und Kommunismus vor.

Von den überlieferten Dokumenten aus dem literarischen Schaffen des jungen Marx enthält der vorliegende Band die Dissertation, mit der Marx im März 1841 seine Studienzeit beendete, und die publizistischen Arbeiten von 1842 bis März 1843. Es handelt sich hier um Ergebnisse selbständiger wissenschaftlicher Arbeit, mit denen Marx in die theoretische und politische Auseinandersetzung seiner Zeit eingriff. Von seinem Werdegang vor dieser Zeit zeugen die ebenfalls in den Band aufgenommenen Abiturarbeiten und die umfangreichen literarischen Versuche. Geben die Abiturarbeiten aus dem Jahre 1835 Kenntnis davon, welche Ideen Karl Marx am Ende seiner Schulzeit beschäftigten, so zeugen die literarischen Versuche, die vorwiegend 1835 bis 1837 entstanden, von geistigen Einflüssen dieser Zeit und von Marx' Bemühen, seinen Gedanken und Gefühlen in poetischer Form Ausdruck zu verleihen.

Die Abiturarbeiten sind die frühesten Materialien, die über Marx' Geisteshaltung vor seinem Eintritt in das wissenschaftliche und politische Leben Aufschluß geben. Der von ihm erreichte Entwicklungsstand wird vor allem dort sichtbar, wo er eigene Ansichten formuliert: in den drei Aufsätzen in den Fächern Deutsch, Religion und Latein. Besonders im Deutschaufsatz wird deutlich, wie die fortschrittlichen Ideen, mit denen Marx im Elternhaus und am Trierer Gymnasium bekannt gemacht wurde, auf ihn wirkten. Es handelt sich hierbei vor allem um das Gedankengut der späten deutschen Aufklärung mit Immanuel Kant als führendem Vertreter sowie um die Ideen der französischen Aufklärung, die im Rheinland eine besondere Rolle spielten. Für Marx war der entscheidende Vermittler der Gedanken der Aufklärung der Direktor des Gymnasiums und führende Repräsentant des geistigen Lebens in Trier, Johann Hugo Wyttenbach. Das zeigt sich unter anderem darin, daß die wichtigsten Gesichtspunkte des deutschen Aufsatzes in Schriften Wyttenbachs nachweisbar sind. Die meisten der von Marx geäußerten Gedanken sind auch in den Arbeiten seiner Mitschüler enthalten. Im wissenschaftlichen Apparat zu den einzelnen Aufsätzen wird ausgeführt, welche Probleme nur bei ihm herausgearbeitet werden.

Bezeichnend für Marx ist, daß bestimmte Ansichten gerade bei ihm auf fruchtbaren Boden fielen und auch später wieder aufgegriffen wurden. Seine eigene Leistung besteht in der Auswahl des Dargebotenen, in der 
Gewichtung sowie in der Art und Weise der Darstellung. Für alle drei Aufsätze ist ein bestimmtes Herangehen charakteristisch: Marx steckt selbst die Grenzen ab, innerhalb derer er die Untersuchung führen will, wobei sich seine Arbeiten durch ein besonders weites Blickfeld auszeichnen. Er formuliert Gesichtspunkte, nach denen er die Darstellung anordnet. Kennzeichnend für Marx ist ferner das Bemühen um ein abgewogenes Urteil. Er versucht, die Dinge und Erscheinungen in ihrer Kompliziertheit, Gegensätzlichkeit und unter Einschluß der negativen Seiten zu erfassen. Alle drei Aufsätze heben sich von den Arbeiten der anderen Schüler durch ihre reiche Sprache ab.

Marx' Geisteshaltung ist an seiner Stellung zu einigen Fragen abzulesen, die im deutschen Aufsatz und im Religionsaufsatz zum Teil in unterschiedlicher, jedoch im wesentlichen sich nicht widersprechender Weise dargestellt werden.

Im Mittelpunkt seiner Überlegungen steht der Gedanke von der Vervollkommnung des einzelnen und der Gesellschaft als Ziel der menschlichen Entwicklung. Im deutschen Aufsatz geht Marx ausführlich auf dieses Thema ein. Die Selbständigkeit des Menschen und das Bewußtsein seiner eigenen Kraft sind Hauptgedanken der Darstellung. Die Verantwortung des Menschen für die Gestaltung seines Schicksals wird - ganz im Sinne der Aufklärung - stark herausgearbeitet und von vielen Seiten beleuchtet, die "Gottheit" tritt in den Hintergrund. Gleichzeitig verweist Marx auf außerhalb des einzelnen Menschen existierende Bedingungen, darauf, daß die „Verhältnisse in der Gesellschaft . . . einigermaßen schon begonnen“ haben, "ehe wir sie zu bestimmen im Stande sind" (S. 455).

Der Religionsaufsatz enthält, wenn auch mit Unterschieden, eine in mancher Hinsicht ähnliche Gedankenführung. In ihm geht Marx zunächst von der Unvollkommenheit und Erlösungsbedürftigkeit der Menschen aus. Die Grundlage für die Vereinigung der Gläubigen mit Christus sucht Marx jedoch bei den Menschen selbst, in ihrer Geschichte, in ihrer Natur, die in der Begeisterung für das Gute und im Streben nach Erkenntnis besteht. Auch die Wirkungen dieser Vereinigung werden in bezug auf die menschliche Tugend untersucht. So orientiert Marx in dem durch das Thema abgesteckten Rahmen auf die menschliche Entwicklung.

Marx behandelt in seinen Aufsätzen auch das Verhältnis zu den anderen Menschen. Dieser Gedanke, der im Religionsaufsatz nur anklingt, nimmt im deutschen Aufsatz breiten Raum ein. Das Wirken für das Wohl der Menschheit ist für Marx das ausschlaggebende Motiv bei der Berufswahl. Der Zusammenhang zwischen der Vollendung des einzelnen und dem Wirken für das Wohl der Allgemeinheit wird in dieser Ausführlichkeit nur von ihm dargelegt. 
Anknüpfend an das Ideengut der Aufklärung, verwies Marx in seinen Abiturarbeiten auf die Vervollkommnung des Menschen und begann - wenn auch noch in abstrakter Form - das Wechselverhältnis zwischen Individuum und Gesellschaft zu erfassen. Damit hatte er wichtige Ausgangspunkte für seine weitere geistige Entwicklung gewonnen.

Aus Marx' ersten Studienjahren in Bonn und Berlin sind umfangreiche literarische Versuche überliefert. Von ihnen war bisher nur eine Gedichtsammlung veröffentlicht worden, die Marx im Frühjahr 1837 seinem Vater zum Geburtstag gewidmet hatte. Erstmals werden im vorliegenden Band nun alle überlieferten poetischen Versuche des jungen Marx der Öffentlichkeit zugänglich gemacht. Sie bestehen aus sieben Sammlungen. Drei von ihnen widmete Marx im Spätherbst 1836 seiner Braut Jenny von Westphalen: "Buch der Liebe. Erster Teil”, „Buch der Liebe. Zweiter Teil” und „Buch der Lieder". Im Frühjahr stellte er die bereits erwähnten „Gedichte, meinem teuren Vater zu seinem Geburtstage 1837" zusammen. Zwei Sammlungen sind in der Abschrift von Marx' Schwester Sophie überliefert: "Gedichte aus den Jahren 1835 und 1836. Zusammengestellt von Sophie Marx" und "Gedichte. Aus einem Notizbuch von Sophie Marx". 1839 fertigte Marx für seine Braut eine „Volksliedersammlung” an.

Bei der Wertung der literarischen Versuche ist davon auszugehen, daß sich Marx damals keineswegs nur mit Poesie befaßte. Wie aus einem umfangreichen Brief an seinen Vater vom 10./11. November 1837 hervorgeht, betrieb er vor allem philosophische und juristische Studien und versuchte sich auf beinahe 300 Bogen an einer Darstellung der Rechtsphilosophie. Außerdem beschäftigte er sich mit deutscher Geschichte und - wohl unter dem Einfluß der an der Bonner Universität gehörten Vorlesungen - mit Kunsttheorie und Kunstgeschichte, insbesondere mit der Geschichte der antiken Kunst. Darüber hinaus übersetzte er lateinische Autoren und betrieb Sprachstudien. Gleichzeitig verfolgte er die zeitgenössische Literatur. Diese Studien dürften einen großen Teil seiner Zeit beansprucht haben und waren für den weltanschaulichen Klärungsprozeß entscheidend. Da die umfangreichen Arbeiten aus diesen Jahren (siehe S. 1274-1277) von Marx selbst vernichtet wurden und außer dem Brief an den Vater keine Zeugnisse dieser Beschäftigung bekannt sind, gewinnen die poetischen Versuche als Quellenmaterial für seine geistige Entwicklung in dieser Zeit Bedeutung. Nach den Abiturarbeiten und neben dem genannten Brief sind sie die einzigen überlieferten schriftlichen Zeugnisse aus den Jahren 1835 bis 1837.

Bereits in seinem großen Bekenntnisbrief an den Vater vom Novem- 
ber 1837 schätzte Marx selbst die Jenny von Westphalen gewidmeten Gedichte sehr kritisch ein: „Alles wirkliche verschwimmt und alles Verschwimmende findet keine Grenze, Angriffe auf die Gegenwart, breit und formlos geschlagenes Gefühl, nichts Naturhaftes, alles aus dem Mond construirt, der völlige Gegensatz von dem, was da ist und dem, was sein soll, rhetorische Reflektionen statt poetischer Gedanken, aber vielleicht auch eine gewisse Wärme der Empfindung und Ringen nach Schwung..." (Karl Marx an Heinrich Marx, 10./11. November 1837. In: MEGA(2) III/1. S. 10.) Auch Laura Lafargue berichtete Franz Mehring, daß ihre Eltern diese Verse sehr respektlos behandelten.

Wenngleich Marx' Jugendgedichte in ästhetischer Hinsicht nur geringe Bedeutung besitzen, vermitteln sie doch eine Reihe neuer Aufschlüsse. Sie sind zunächst von biographischem Interesse, geben doch gerade poetische Schriften Einblick in die Gedanken- und Gefühlswelt ihres Verfassers. So bieten auch die poetischen Jugendarbeiten von Marx dem Leser die Möglichkeit, dessen geistige Einflußsphäre zu erhellen, die Eindrücke nachzuerleben, den Wechsel der Stimmungen zu verfolgen und die Konflikte nachzuempfinden, mit denen sich der Jüngling in einer Phase des schöpferischen Ringens um die Klärung grundlegender weltanschaulicher Fragen auseinanderzusetzen hatte.

Die literarischen Versuche von Karl Marx bezeugen vor allem, wie er fest im geistigen und kulturellen Leben seiner Zeit und ihrer Tradition wurzelte. Er kannte die Literatur und schöpfte aus ihr in thematischer wie gestalterischer Hinsicht. Bereits die Titel seiner Gedichtsammlungen weisen auf literarische Vorbilder. Als er im Spätherbst 1836 zwei Sammlungen „Buch der Liebe" nannte, war in demselben Jahr unter diesem Titel ein Gedichtbändchen von Hoffmann von Fallersleben erschienen. Auch ein Teil des "West-östlichen Divans" von Johann Wolfgang von Goethe war so benannt. Der Bezug des „Buchs der Lieder“ zu der gleichnamigen Sammlung von Heinrich Heine liegt auf der Hand. In ihrer Gesamtheit lassen die literarischen Versuche deutlich werden, welche Ideen in dieser Zeit seine Geisteshaltung prägen halfen, wobei die im vorliegenden Band erstmals veröffentlichten Gedichtsammlungen gestatten, diese Einflüsse umfassender und präziser zu umreißen.

So widerspiegeln sich in Marx' Lyrik Elemente verschiedener Entwicklungsphasen der deutschen Literatur. Neben Zügen der romantischen Dichtung, wie sie bei Ludwig Uhland und Nikolaus Lenau ihren Ausklang findet, ist in seinen Gedichten eine starke weltanschauliche wie formalästhetische Einwirkung der Klassik festzustellen. In seinen Sonetten über Goethe und Schiller, die bisher nicht bekannt waren, bestätigt der junge Marx selbst den Vorbildcharakter, den die klassische deutsche Literatur 
für ihn hatte. Dazu mag auch die Tatsache beigetragen haben, daß die Romantik im Trierer Raum in den ersten Jahrzehnten des 19. Jahrhunderts nur geringen Einfluß gewann. Marx kam mit ihr vor allem an der Bonner Universität durch die Vorlesungen August Wilhelm Schlegels und sicher im „Poetenkränzchen“ in Berührung. Seine gediegene klassische, an der Aufklärung orientierte Bildung war eine Voraussetzung dafür, daß er nicht einem mystischen und reaktionären Romantizismus verfiel, sondern sehr bald die Wertlosigkeit seiner literarischen Versuche erkannte und sich wieder stärker philosophischen und juristischen Studien zuwandte.

Der überwiegende Teil der Gedichte ist Liebeslyrik. Hierzu gehören die Jenny von Westphalen gewidmeten Gedichte, die er häufig in die anspruchsvolle Form von Sonetten kleidete. Eine weitere Gruppe sind phantastische Balladen und Romanzen, teils an historische Vorgänge angelehnt. Daneben stehen zahlreiche Stücke, die Marx' Ringen um einen weltanschaulichen Standpunkt widerspiegeln. Besonderes Interesse verdienen eine Reihe von Epigrammen, die vor allem in dem seinem Vater gewidmeten Gedichtband enthalten sind.

Romantische Stimmungen kommen in Marx' Gedichten vor allem dort auf, wo er dem unruhvollen Suchen nach einem klaren Standpunkt, der quälenden Ungewißheit über die Liebe seiner heimlichen Verlobten Ausdruck verleiht. Jedoch berechtigt die häufige Gestaltung des Motivs unerfüllter oder unglücklicher Liebe keineswegs dazu, Marx' Gedichte als durchweg romantisch zu werten. Vielmehr sind hier deutliche Bezüge zu Gedichten Goethes (vgl. etwa „Der untreue Knabe“) zu erkennen. Bereits Franz Mehring hatte auf Bezüge zu Schillers Laura-Gedichten verwiesen (Aus dem literarischen Nachlass von Karl Marx, Friedrich Engels und Ferdinand Lassalle. Hrsg. v. Franz Mehring. I. Ges. Schriften v. Karl Marx u. Friedrich Engels. März 1841 bis März 1844. Stuttgart 1902. S. 27). In der im Notizbuch von Sophie Marx überlieferten Fassung des Gedichts "Die zwei Himmel" taucht auch der Name Laura auf. Auch Marx' Bild der Geliebten als ebenbürtiger geistiger Partnerin wie seine Liebesauffassung überhaupt, in der die Liebe als eine Kraft begriffen wird, die den Mann zu großen Taten beflügelt und dessen schöpferische Anlagen zur Entfaltung bringt, weisen in die Nähe der Klassik (,Der Gedanken“, „Menschenstolz”, „Umwandelung", "An Jenny").

Eindeutig in der Tradition der klassischen Weltanschauungslyrik Schillers und Goethes stehen die Gedichte, die Marx' Streben nach Wahrheit, seine Verehrung des Schönen zum Ausdruck bringen. Die Gedichte, in denen er sein Drängen nach großen Taten gestaltet, knüpfen an die im deutschen Abituraufsatz entwickelten Ideen an: 
„Darum laßt uns alles wagen,

Nimmer rasten, nimmer ruhn;

Nur nicht dumpf so gar nichts sagen,

Und so gar nichts woll'n und thun." (S. 536.)

Diese Gedichte enthalten Anklänge an das klassische Ideal des gesellschaftlich tätigen Menschen, mit dem sich Marx zu dieser Zeit identifiziert (,Meine Welt", ,Empfindungen "). In diesem Zusammenhang taucht auch das Faustmotiv auf (,Das Gespenst"). Unmittelbar auf Motive aus dem zweiten Teil von Goethes "Faust" verweisen Bildwahl und Versmaß von "Glöckners Turmlied", ,Lied der Elfen" und "Lied der Gnomen”. Ähnliche Bezüge bestehen zwischen „Erwachen" und Goethes „Gesang der Geister über den Wassern". Auch der von den Romantikern häufig eingeführten Gestalt des Sängers, den Marx in vielen Gedichten zum Sprecher seiner Gedanken macht, begegnen wir oft in Goethes Lyrik.

An die romantische Schicksalstragödie lehnt sich der überlieferte Akt des Trauerspiels "Oulanem" an, während das Romanfragment „Scorpion und Felix" Einflüsse von E.T.A. Hoffmann erkennen läßt, dessen „Elixiere des Teufels" Marx auch erwähnt. Dieses Prosastück trägt realistische Züge, die in die Nähe der Epigramme weisen: Die satirische Schilderung des Berliner Spießerlebens, die Kritik an der Wiedereinführung der Majorate, an der Deutschtümelei und der Frömmelei.

Die Epigramme, die sich kritisch mit Zeiterscheinungen auseinandersetzen, enthalten konkretere Aussagen. Sie widerspiegeln Marx' Hinwendung zum wirklichen Leben und damit einen Fortschritt in seiner Entwicklung. Hier wie auch in der Prosa seines Romanfragments findet er in der polemischen Satire, in der Art und Weise der Zuspitzung mitunter schon einen originellen Ton.

Erste politische Stellungnahmen werden abgegeben gegen die deutschtümelnden Burschenschafter und das bornierte deutsche Kleinbürgertum (,Epigramme. I.", ,Epigramme. III."). Satirisch geißelt Marx das kulturelle Niveau seiner Umgebung (,Armida von Ritter Gluck"). Hierzu gehört auch die ironische Abrechnung mit den verschiedenen Kritikern Goethes und Schillers, allen voran dem konservativ-pietistischen Johann Friedrich Wilhelm Pustkuchen. Die Epigramme auf die exakten Wissenschaften (Mathematik, Medizin, Chemie) zielen gegen das Philiströse im Verhalten vieler ihrer Vertreter. In den Epigrammen gegen Hegel wird deutlich, daß Marx diesem zunächst noch ablehnend gegenübersteht.

Die literarischen Versuche sind als eine Durchgangsstufe in der Entwicklung des jungen Marx zu betrachten, die für sein weiteres Schaffen nicht ohne Bedeutung blieb. Sie halfen ihm, seine wirklichen Fähigkeiten 
zu entdecken und ein echtes Verständnis für große künstlerische Leistungen zu entwickeln.

Das Bemühen, zu reimen oder sich auch in anderen literarischen Gattungen zu versuchen, kam der hohen sprachlichen Begabung von Marx entgegen. Frühzeitig stieß er so auf die Schwierigkeiten sprachlicher Bewältigung von Gedankeninhalten. Insofern waren die literarischen Versuche eine wichtige Schule. Für den brillanten Stil, die geschliffene Sprache, die seine späteren wissenschaftlichen und publizistischen Arbeiten auszeichnen, war das mühsame Ringen um den poetischen Ausdruck sicher nicht ohne Einfluß.

Mit der Abhandlung „Differenz der demokritischen und epikureischen Naturphilosophie" promovierte Marx zum Doktor der Philosophie. Die Dissertation entstand zwischen Mitte 1840 und März 1841, d.h. inmitten eines Lebensabschnitts von Marx, in dem er sich auf der Suche nach einem politischen Standpunkt, nach einer wissenschaftlichen Erklärung der Welt zur Philosophie Hegels bekannt hatte und Junghegelianer geworden war. Der Untersuchung des Gegenstandes der Dissertation lag das politisch-theoretische Bedürfnis der Junghegelianer um Bruno Bauer zugrunde, die nacharistotelischen Systeme, die epikureische, stoische und skeptische Philosophie, für die Begründung ihrer Philosophie des Selbstbewußtseins, ihrer atheistischen und bürgerlich-demokratischen Anschauungen zu benutzen.

Der Ausarbeitung der Dissertation gingen 1839 umfangreiche Studien der Philosophie Epikurs voraus, die in den ,Heften zur epikureischen Philosophie" (siehe MEGA $\$$ IV/1) ihren Niederschlag fanden. Die Dissertation selbst sollte der „Vorläufer einer größern Schrift" sein, in der Marx „ausführlich den Cyklus der epikuräischen, stoischen und skeptischen Philosophie in ihrem Zusammenhang mit der ganzen griechischen Speculation darstellen" wollte (S. 13).

Marx' Beschäftigung mit dem Epikureismus, Stoizismus und Skeptizismus widerspiegelt sein außerordentliches Interesse für die Geschichte der Philosophie, das von $\mathrm{Hegel}$ inspiriert war und das er mit seinen junghegelianischen Freunden teilte. Hegel hatte die Geschichte der Philosophie als einen gesetzmäßig zusammenhängenden Erkenntnisprozeß behandelt, der die objektive Idee zum Inhalt habe. Die einzelnen philosophischen Systeme erklärte er als historische Entwicklungsstufen, die deshalb nur als Philosophien ihrer Zeit erfaßt und dargestellt werden könnten. Diese dialektische Interpretation der Geschichte des philosophischen Denkens, die zu den wertvollsten Teilen der Hegelschen Philosophie gehörte, rief 
in den dreißiger Jahren des 19. Jahrhunderts eine heftige ideologische Auseinandersetzung hervor. Es zeugt von Marx' großem Verständnis für Hegels Dialektik und deren progressiven Gehalt, wenn er betont, daß mit „dem bewunderungswürdig-großen und kühnen Plan” Hegels „überhaupt erst die Geschichte der Philosophie datirt werden kann" (S. 13/14).

Marx stimmte Hegel zu, wenn dieser den Epikureismus, Stoizismus und Skeptizismus als objektiv notwendige Entwicklungsstufe der Geschichte der griechischen Philosophie charakterisierte, die als Reaktion auf Aristoteles' System den allgemeinen Standpunkt des Selbstbewußtseins repräsentiere. Marx kritisierte jedoch an seinem Lehrmeister, daß es ihm nicht gelungen sei, die wirkliche Bedeutung dieser Systeme zu erkennen. Da Hegel das Selbstbewußtsein der absoluten Idee unterordnete, spielten die antiken „Philosophien des Selbstbewußtseins" bei ihm nicht die entscheidende Rolle. Für Marx dagegen waren diese „,Systeme ... der Schlüssel zur wahren Geschichte der griechischen Philosophie" (S. 14). Ging Hegel von der Identität von Denken und Sein aus und ließ er die Entwicklung der Idee in seinem System abschließen, so lösten die Junghegelianer diese Identität auf und nahmen eine unendliche dialektische Entwicklung an. Dabei rückten sie das Selbstbewußtsein als Triebkraft der Umgestaltung des Bestehenden in den Vordergrund. Dieses allgemeine Prinzip der Junghegelianer auf die Geschichte angewandt, mußte auch die epikureische, stoische und skeptische Philosophie eine weit bedeutendere Rolle spielen, zumal sich die historischen Parallelen zwischen der nacharistotelischen und nachhegelschen Philosophie aufdrängten. „Es ist erst jezt die Zeit gekommen", schrieb Marx, , in der man die Systeme der Epikuräer, Stoiker und Skeptiker verstehn wird. Es sind die Philosophien des Selbstbewußtseins." (S. 92.)

In der Dissertation untersuchte Marx eine Seite des Zusammenhangs der epikureischen, stoischen und skeptischen Philosophie mit der älteren griechischen Philosophie, und zwar das Verhältnis der epikureischen zur demokritischen Naturphilosophie. Diese Untersuchung war wegen der Verfälschung der Lehre Epikurs, der weitverbreiteten Abwertung seiner Atomistik sowie der zeitgenössischen Auseinandersetzung über Fragen der Naturphilosophie und der Freiheit des menschlichen Individuums von besonderem Interesse.

Aus Marx' junghegelianischer Position in jener Zeit ist erklärbar, warum er sich nicht für den Materialismus Epikurs und Demokrits interessierte. Deshalb wird Marx auch der historischen Bedeutung Demokrits nicht gerecht, und es gelingt ihm nur bedingt, die Genialität von Epikurs Atomistik zu erfassen. Der Atheist und Dialektiker Marx jedoch stieß auf Erkenntnisse, die bleibenden Wert behielten und ihn zu der Schlußfolge- 
rung kommen ließen, daß Epikur „der größte griechische Aufklärer" ist (S. 57).

Von zentraler Bedeutung war für Marx, daß Epikur durch die „,Deklination des Atoms von der geraden Linie" den strengen Determinismus Demokrits aufzuheben und dadurch die Willensfreiheit, die Individualität und die Selbständigkeit des menschlichen Individuums auf natürliche Weise zu erklären versuchte. Marx wies nach, daß die Deklination des Atoms nur der spezifische Ausdruck eines allgemeinen Gesetzes der epikureischen Philosophie ist. Damit deckte Marx den Zusammenhang zwischen Epikurs Naturphilosophie und seiner Gesellschaftslehre auf und zeigte, daß die Atomistik Epikurs eine wichtige Rolle für die Begründung seiner ethischen Ansichten spielte. Die Gegenüberstellung von demokritischer und epikureischer Naturphilosophie führte Marx zu der Schlußfolgerung, daß „die Absolutheit und Freiheit des Selbstbewußtseins... das Princip der epikureischen Philosophie" sei (S.57) und bei Epikur "die Atomistik mit allen ihren Widersprüchen als die Naturwissenschaft des Selbstbewußtseins ... durchgeführt und vollendet" ist (S. 58).

Diese philosophische Interpretation war primär von Hegels Idealismus geprägt, wies aber in der Einschätzung der Atomistik Epikurs und ihrer Bedeutung im Gesamtsystem seiner Lehre erhebliche Unterschiede zu Hegels Ansichten auf. Hegel hatte die Naturphilosophie Epikurs sehr abwertend beurteilt und ihr keine Bedeutung für die Entwicklung des philosophischen Denkens eingeräumt. Marx' Definition des Prinzips der epikureischen Philosophie deutete aber auch Unterschiede zu den Ansichten anderer Junghegelianer an. „Wird das abstract-einzele Selbstbewußtsein als absolutes Princip gesetzt: so ist zwar alle wahre und wirkliche Wissenschaft in so weit aufgehoben, als nicht die Einzelheit in der Natur der Dinge selbst herrscht. Allein zusammenstürzt auch Alles, was gegen das menschliche Bewußtsein sich transcendent verhält, also dem imaginirenden Verstande angehört. Wird dagegen das Selbstbewußtsein, das sich nur unter der Form der abstracten Allgemeinheit weiß, zum absoluten Princip erhoben: so ist der abergläubischen und unfreien Mystik Thür und Thor geöffnet." (S. 57.)

Hier deutete Marx eine Auffassung an, die er in einer Anmerkung, in der er historische Parallelen zu Hegel und seinen Schülern zog, noch näher begründete. In diesen Ausführungen wird offenkundig, daß das Verhältnis von Philosophie und Wirklichkeit ein zentrales Problem von Marx' Ringen um eine wissenschaftliche Weltanschauung war. Er faßte dieses Verhältnis als einen dialektischen Prozeß. Die Aufhebung der Hegelschen Identität von Denken und Sein und die Hervorhebung des Selbstbewußtseins als das aktivierende, verändernde Moment in der Entwicklung trieb Marx nicht 
bis zur einseitigen Verselbständigung voran und erhob das Selbstbewußtsein nicht zum absoluten Prinzip. Er wies nach, daß auch die Verabsolutierung des Selbstbewußtseins für übernatürliche Erklärungen der Welt Raum schafft. Für Marx gibt es in der Entwicklung Momente, wo die Welt mit der Vernunft übereinstimmt, die Philosophie sich mit der Welt in Harmonie befindet, die Einheit von Denken und Sein hergestellt ist. Auf diesen Zustand folgen Momente, wo der theoretische Geist, die Philosophie, in Gegensatz zur wirklichen Welt gerät, sich gegen diese kehrt, die Welt unvernünftig wird, die Philosophie aktiv auf die wirkliche Welt einwirken muß, um sie wieder vernünftig zu machen. Marx versuchte mit dieser Auffassung die objektiv-idealistische Hegelsche Dialektik im Sinne einer unendlichen widersprüchlichen Entwicklung von Philosophie und wirklicher Welt anzuwenden. Das führte ihn zu der Konsequenz, „daß das Philosophisch-werden der Welt zugleich ein Weltlich-werden der Philosophie" sei (S.68). Damit grenzte Marx sich von subjektiv-idealistischen Momenten ab, die bereits zur damaligen Zeit in der junghegelianischen Geschichtsauffassung vorhanden waren, und begann, in seinem philosophischen Denken eigene Wege zu beschreiten. Die eigenständige Interpretation der dialektischen Wechselwirkung zwischen Philosophie und Wirklichkeit wurde ein wichtiger Ausgangspunkt für die weitere Entwicklung von Marx' Weltanschauung.

Marx führte den Kampf gegen die historisch überlebte, unvernünftig gewordene wirkliche Welt vorerst nur auf philosophischem Gebiet, weil er wie Bruno Bauer und andere Junghegelianer davon überzeugt war, daß die Theorie die stärkste Praxis sei. , Allein die Praxis der Philosophie ist selbst theoretisch. Es ist die Kritik, die die einzelne Existenz am Wesen, die besondere Wirklichkeit an der Idee mißt." (S. 68.) Da Marx der philosophischen Kritik die Aufgabe zusprach, auf die unvernünftig gewordene Welt einzuwirken, um sie wieder vernünftig zu machen, deuteten sich auch hier im Keim Unterschiede zur abstrakten, im reinen theoretischen Denken befangenen Kritik anderer Junghegelianer an.

Im Hinblick auf Marx' weitere philosophische Entwicklung ist es von Interesse, daß er bereits zu dieser Zeit die Kritik am Hegelschen System anders ansetzte als viele Junghegelianer. Er wandte sich gegen diejenigen Hegelschüler, die „diese oder jene Bestimmung seines Systems aus Accommodation u.dgl., mit einem Wort, moralisch erklären" (S. 67). Hier und an anderer Stelle spürt man die große Hochachtung, die Marx Hegel entgegenbrachte. Er bezeichnete es als gewissenlos, Hegel unlautere Absichten vorzuwerfen, und betonte, daß Hegel die Wissenschaft stets als werdende behandelt habe. Marx spricht aus, daß möglicherweise die Mängel der Hegelschen Philosophie ,,in einer Unzulänglichkeit oder 
unzulänglichen Fassung seines Princips selber ihre innerste Wurzel" haben (S. 67).

Wie alle Junghegelianer war Marx überzeugter und streitbarer Atheist. Er trat gegen die Religion, gegen die Unterdrückung der Philosophie und des Individuums durch die Religion auf und forderte die Befreiung des Menschen von religiöser Vormundschaft. Das Bekenntnis des Prometheus, „mit einem Wort, ganz hass' ich all' und jeden Gott", machte er zum Bekenntnis seiner Philosophie und erklärte „das menschliche Selbstbewußtsein" als die „oberste Gottheit" (S. 14). Die Parteinahme für die atheistischen Züge der epikureischen Philosophie war ein Grundzug seiner Dissertation. Er hob hervor, daß Epikur den Einfluß der Götter auf das Geschehen in Natur und Geschichte ablehnte, in der menschlichen Dummheit und Angst eine wesentliche Voraussetzung der Religion sah und die Menschen von der Furcht vor den Göttern befreien wollte. Den Atheismus Epikurs verteidigte Marx vor allem in einer Polemik mit Plutarch, weil für ihn Plutarchs Standpunkt typisch war für das Verhältnis der Theologie zur Philosophie überhaupt. Die Auseinandersetzung mit Plutarch schlug sich bereits in den „Heften zur epikureischen Philosophie" sowie in einer nur teilweise überlieferten selbständigen Ausarbeitung (siehe MEGA (2) IV/1, S. 59-61 und 151-152) nieder und sollte als Anhang zur Dissertation veröffentlicht werden. Leider ist von diesem Anhang nur ein Teil der Anmerkungen überliefert. Diese Anmerkungen sind jedoch von Interesse, weil Marx sich hier mit den sogenannten Beweisen für das Dasein Gottes auseinandergesetzt hat. Diesen angeblichen Beweisen setzte Marx entgegen: ', ,weil die Natur schlecht eingerichtet ist, ist Gott' ${ }^{\prime}$, weil eine unvernünftige Welt ist, ist Gott.' "Weil der Gedanke nicht ist, ist Gott." (S. 91.) Marx lenkte damit im Ansatz darauf hin, daß in der Wirklichkeit selbst die Ursachen für die Existenz der Religion liegen. Er stieß damit zu einigen bleibenden Erkenntnissen über die Ursachen und die Rolle der Religion bei der Unterdrückung des menschlichen Individuums vor, die wichtige Ansatzpunkte seiner weiteren philosophischen Entwicklung wurden.

Die Dissertation dokumentierte bereits Fähigkeiten der wissenschaftlichen Analyse, Auseinandersetzung, Beweisführung und Schlußfolgerung, die Marx in seiner weiteren wissenschaftlichen Arbeit beibehielt und vervollkommnete. Auch deutete sich bereits in dieser ersten für die Veröffentlichung vorgesehenen Arbeit an, daß die Auseinandersetzung mit der reaktionären Ideologie immanenter Bestandteil der wissenschaftlichen Arbeit von Marx werden sollte. Da der Gegenstand der Dissertation nur bedingt die Möglichkeit der Polemik mit solchen Ansichten bot, nutzte Marx das Vorwort sowie die Anmerkungen, um direkt auf aktuelle Parallelen aufmerksam zu machen. So widerspiegeln gerade diese Teile der Disser- 
tation am deutlichsten die Teilnahme von Marx an den politisch-theoretischen Kämpfen seiner Zeit.

Als Marx die Berliner Universität verließ, um sich für eine Lehrtätigkeit an der Bonner Universität vorzubereiten, stand er noch auf dem Boden des philosophischen Idealismus und stimmte in den meisten philosophischen Grundfragen mit seinem damaligen engsten Weggefährten Bruno Bauer überein. Aber das tiefe Verständnis für den rationellen Gehalt der Hegelschen objektiv-idealistischen Dialektik und für Hegels historisches Herangehen ließ Marx zu eigenständigen Schlußfolgerungen über die Wechselwirkung von Philosophie und Wirklichkeit, über das Verhältnis von Denken und Sein, über die Rolle des Selbstbewußtseins im historischen Entwicklungsprozeß kommen, die Ausgangspunkt für eine objektivere und realistischere Betrachtung der gesellschaftlichen Wirklichkeit wurden und ihn vor subjektiv-idealistischen Tendenzen bewahrten.

Die publizistischen Arbeiten von Marx widerspiegeln eine neue Etappe seiner politischen und philosophischen Entwicklung. Erstmals beteiligte sich Marx an der politischen Auseinandersetzung. Er suchte das Bündnis von Philosophie und Politik.

Dieser Eintritt von Marx ins politische Leben, die Herausbildung und Entwicklung seines revolutionär-demokratischen Standpunktes fiel in eine Zeit, da die Bourgeoisie in Deutschland begonnen hatte, sich als Klasse zu konstituieren, und die liberale Bourgeoisie zur offenen Opposition gegen das bestehende politische System übergegangen war. Für Marx' publizistische Tätigkeit wurde bedeutungsvoll, daß er in der Rheinprovinz, dem sozialökonomisch fortgeschrittensten Teil Preußens, wirkte. Durch die hier teilweise vollzogene Liquidierung feudaler Eigentums- und Rechtsverhältnisse vollzog sich der Kampf der bürgerlichen Opposition für eine konstitutionelle Monarchie und um die Erhaltung der bürgerlichen Errungenschaften unter fortgeschritteneren Bedingungen und erbrachte deshalb auch dementsprechend reifere politische Erfahrungen. Von entscheidender Bedeutung für Marx' Entwicklung war die Herausbildung einer demokratischen Strömung innerhalb der Oppositionsbewegung. Diese Strömung verteidigte die Grundinteressen des Volkes, bejahte die revolutionäre Aktion und kämpfte für bürgerlich-demokratische Verhältnisse. Marx selbst beeinflußte diese demokratische Strömung vor allem als Mitarbeiter und Redakteur der ",Rheinischen Zeitung".

Marx begann seine Mitarbeit an der "Rheinischen Zeitung“ im Mai 1842 und wurde am 15. Oktober des gleichen Jahres Redakteur des Blattes. Hatte er schon vorher auf die politische Gestaltung der Zeitung Einfluß 
genommen, so veränderte er als Redakteur das politische Profil des Organs. Durch seine Artikel prägte er in entscheidendem Maße die Richtung der Zeitung, er erhöhte maßgeblich deren politischen Einfluß und führte einen prinzipiellen und taktisch klugen Kampf gegen die Versuche der Regierung, die Tendenz der Zeitung zu verändern oder sie ganz zu liquidieren. Unter der Leitung von Marx vertrat die „Rheinische Zeitung” immer zielstrebiger und bewußter revolutionär-demokratische Ansichten, sie wurde das bedeutendste oppositionelle Blatt in Deutschland und das wichtigste Zeugnis für das Fortbestehen und die weitere Ausprägung einer demokratischen Strömung in der antifeudalen Opposition. Nicht nur in der Geschichte der deutschen, sondern der gesamten europäischen Presse nimmt die „Rheinische Zeitung" einen hervorragenden Platz ein, weil sie einige Jahre vor der Revolution von 1848/49 das Herannahen dieses revolutionären Ereignisses ankündigte.

Für Marx' eigene politische und theoretische Entwicklung war der Beginn der Tätigkeit in der Redaktion von außerordentlicher Bedeutung. Die politischen Erfahrungen und Einsichten, zu denen er als Redakteur gelangte, die unmittelbare Berührung mit wesentlichen politischen und ökonomischen Forderungen der Oppositionsbewegung sowie die tägliche Auseinandersetzung mit der widersprüchlichen öffentlichen Diskussion über diese Forderungen, die ständigen Angriffe auf die Redaktion der "Rheinischen Zeitung" von seiten der Regierung, der Zensurbehörden und anderer Zeitungen förderten Marx' theoretischen Erkenntnisfortschritt und machten seine politischen Schlußfolgerungen konsequenter.

Marx orientierte sich in seiner publizistischen Tätigkeit auf die brennendsten politischen Probleme seiner Zeit. Dazu gehörten die Forderung nach Pressefreiheit, die Kritik der preußischen Zensurgesetzgebung, der Kampf gegen das Verbot der fortschrittlichen Presse, die Kritik der feudalständischen Vertretungen und die Forderung nach einer Volksvertretung, die Auseinandersetzung mit der preußischen Gesetzgebung und ihren ideologischen Grundlagen, die Bewegung für eine Kommunalreform und die Kritik an den Versuchen, die bürgerliche Rechtsgleichheit von Stadt und Land zu beseitigen. Insgesamt handelte es sich um eine Auseinandersetzung mit den historisch überlebten politischen Verhältnissen in Preußen, um eine Kritik am preußischen Staat und seinen sozialen Grundlagen, um die Verteidigung oder Sicherung demokratischer Rechte für das gesamte Volk.

Marx kam während seiner publizistischen Tätigkeit erstmals mit sozialen und ökonomischen Fragen in Berührung. Er beschäftigte sich mit der Lage und den Interessen der besitzlosen Masse sowie der Armut und dem Ruin der Moselbauern. Er untersuchte den Zusammenhang zwischen 
Eigentum an Grund und Boden und politischer Interessenvertretung. Zum erstenmal nahm er zu den Ideen des französischen utopischen Sozialismus und Kommunismus Stellung.

In der politischen Auseinandersetzung überprüfte Marx seine philosophischen Ansichten, entwickelte und begründete sie an Hand der konkreten politischen Verhältnisse. Marx stand auch zu Beginn der publizistischen Tätigkeit noch auf dem Boden des philosophischen Idealismus. Er orientierte sich an Hegels objektiv-idealistischer Geschichtsdialektik und erfaßte das gesellschaftliche Leben und das Handeln der Menschen als gesetzmäßigen geschichtlichen Prozeß, der sich unabhängig vom Bewußtsein des einzelnen Individuums vollzog, in dem aber geistige Vorgänge, Zusammenhänge und Triebkräfte die entscheidende Rolle spielten und der geistigen Tätigkeit sowie den geistigen Kämpfen das Primat zukam. Im Mittelpunkt von Marx' philosophisch-theoretischen Analysen in den publizistischen Beiträgen standen seine staats- und rechtsphilosophischen Ansichten, die auch Gegenstand einer nicht überlieferten Kritik der Hegelschen Rechtsphilosophie waren, mit deren Ausarbeitung Marx Ende 1841 begonnen hatte. Marx glaubte an die Möglichkeit, einen über den Klassen stehenden, das Interesse aller Menschen verkörpernden und die Freiheit des ganzen Volkes garantierenden Vernunftstaat zu verwirklichen. Die Analyse der politischen Verhältnisse, Zusammenhänge und Auseinandersetzungen wurde zum Prüfstein seiner theoretischen Ansichten. Nach und nach traten realistischere Momente in den Vordergrund. Schon wenige Monate später ließen ihn die unmittelbaren politischen Erfahrungen den Widerspruch zwischen den politischen Realitäten und seiner philosophischen Weltanschauung erkennen.

In seinem ersten publizistischen Beitrag „Bemerkungen über die neueste preußische Zensurinstruktion" nahm Marx eine grundsätzliche Charakteristik der preußischen Zensurgesetzgebung vor und begründete die Notwendigkeit der Pressefreiheit. Er bewies, daß der preußische Polizeistaat mit seiner Zensurgesetzgebung nicht die Gleichheit der Staatsbürger vor dem Gesetz garantierte, sondern die Interessen der reaktionären Kräfte verteidigte, deren politische Ansichten zum Gesetz erhob, um oppositionelle Auffassungen zu unterdrücken, und daß er sich damit ,in principiellen Gegensatz gegen das Volk setzt" (S. 108). Wenn Marx schlußfolgerte, die „eigentliche Radicalcur der Censur wäre ihre Abschaffung; denn das Institut ist schlecht, und die Institutionen sind mächtiger, als die Menschen" (S. 118), so lagen darin Konsequenzen, die den preußischen Staat überhaupt betrafen.

In dem Artikel „Debatten über Preßfreiheit und Publikation der Landständischen Verhandlungen" kam Marx wieder auf das Thema Zensur und 
Pressefreiheit zurück. Er verlangte uneingeschränkte Pressefreiheit. Sie war für ihn Verwirklichung der Freiheit des Menschen und zugleich notwendige Voraussetzung zur Veränderung der realen Wirklichkeit. Die gesetzliche Anerkennung der Pressefreiheit, forderte Marx, müsse durch ein Pressegesetz geschehen. Dieses sei wirkliches Gesetz, weil in ihm „die Freiheit ein unpersönliches, theoretisches, von der Willkühr des Einzelnen unabhängiges Dasein gewonnen" habe (S.150), weil es das bewußte Spiegelbild innerer Lebensgesetze des menschlichen Handelns sei, weil dadurch die Freiheit vom Staat rechtlich anerkannt werde.

In dem Artikel „Bemerkungen über die neueste preußische Zensurinstruktion" kritisierte Marx erstmals die Religion unter politischen Aspekten und verlieh damit seinem atheistischen Standpunkt neue Züge. Er verurteilte die gesetzlich sanktionierte Unterdrückung der Religionskritik durch die preußische Zensur und verlangte, der Staat müsse sich nicht auf den Glauben, sondern auf die Vernunft gründen. In dem Beitrag „Der leitende Artikel in Nr.179 der ,Kölnischen Zeitung"' setzte sich Marx erneut mit der Religion als ideologischer Grundlage des preußischen Staates auseinander Marx charakterisierte die Religion als historische Erscheinung, deckte den Widerspruch zwischen der Religion und der sich ständig entwickèlnden Wissenschaft auf und legte dar, wie die Religion diesen Fortschritt zu verhindern suchte, sich aber im nachhinein dieser fortschreitenden Entwicklung anpassen mußte. Marx widerlegte die reaktionäre feudale Staatsdoktrin, daß die Religion die natürliche Grundlage jedes Staates sei, und hielt ihr die Entwicklung der bürgerlichen Staatstheorie von Montesquieu bis Hegel entgegen. Noch definiert Marx im Sommer 1842 ,den Staat als den großen Organismus, in welchem die rechtliche, sittliche und politische Freiheit ihre Verwirklichung zu erhalten hat und der einzelne Staatsbürger in den Staatsgesetzen nur den Naturgesetzen seiner eigenen Vernunft, der menschlichen Vernunft gehorcht" (S. 189).

Die Auseinandersetzung mit dem Leitartikel der „Kölnischen Zeitung” widerspiegelt besonders Marx' intensive Beschäftigung mit theoretischen Fragen, die er in der nicht überlieferten Abhandlung "Über Religion und Kunst mit besondrer Beziehung auf christliche Kunst" und der ebenfalls nicht überlieferten „Kritik der Hegelschen Rechtsphilosophie“ behandelt hatte. In diesem Zusammenhang beschäftigte sich Marx auch mit Feuerbach und teilte Ruge mit, daß er ,über das allgemeine Wesen der Religion... einigermaßen mit Feuerbach in Collision gerathe, eine Collision, die nicht das Prinzip, sondern seine Fassung betrifft" (Marx an Ruge, 20. März 1842. In: MEGA (2) III/1. S. 25). Die Polemik mit der „Kölnischen Zeitung" bezeugt auch, daß Marx mit Feuerbach darin übereinstimmte, daß die „Dogmen des Christenthums... keine Dogmen der 
Vernunft" seien (S. 185). Jedoch belegt neues Quellenmaterial über Feuerbach eindeutig, daß der Artikel „Luther als Schiedsrichter zwischen Strauß und Feuerbach", ein enthusiastisches Bekenntnis zu Feuerbachs Philosophie, nicht von Marx verfaßt ist (siehe dazu S.966-967). Unter dieser Voraussetzung muß eingeschätzt werden, daß Marx die Schriften Feuerbachs aufmerksam verfolgte, studierte, analysierte und sich wichtige Erkenntnisse dieser Arbeiten zu eigen machte, er aber Anfang 1842 Feuerbach kritischer beurteilte, seiner Hegelkritik nicht folgte, nicht annahm, es gäbe „keinen anderen Weg... zur Wahrheit und Freiheit, als durch den Feuer-bach" (Luther als Schiedsrichter zwischen Straußund Feuerbach. In: MEGA ${ }^{\circledR}$ 1/1,1. S. 175). Diese Stellung von Marx zu Feuerbach entspricht auch der philosophischen und politischen Entwicklung jener ersten Monate des Jahres 1842. Gegen Ende seiner Tätigkeit an der „Rheinischen Zeitung" studierte Marx Feuerbachs „Thesen zur Reformation der Philosophie" und schlußfolgerte: „Feuerbachs Aphorismen sind mir nur in dem Punkt nicht recht, daß er zu sehr auf die Natur und zu wenig auf die Politik hinweist. Das ist aber das einzige Bündniß, wodurch die jetzige Philosophie eine Wahrheit werden kann." (Marx an Ruge, 13. März 1843. In: MEGA (2) II/1. S. 45.)

Die Polemik mit der „Kölnischen Zeitung“ veranlaßte Marx außerdem, seine Gedanken über die historische Aufgabe der Philosophie darzulegen und ihr Auftreten in der Tagespresse als ein notwendiges Erfordernis der Zeit zu begründen. Damit entwickelte er seine bereits in der Dissertation dargelegten Gedanken unter politischen Gesichtspunkten weiter. Marx ging davon aus, daß die Philosophie die gesetzmäßig notwendig gewordene gesellschaftliche Veränderung geistig vorwegnimmt, „die geistige Quintessenz ihrer Zeit ist" (S. 183) und deshalb in einen Gegensatz zur realen Wirklichkeit gerät. Hat die Entwicklung des Widerspruchs von Philosophie und realer Wirklichkeit eine bestimmte Stufe erreicht, müsse die Philosophie notwendig mit der Wirklichkeit in Wechselwirkung treten, zur Philosophie der Gegenwart werden und die reale Wirklichkeit verändern. Dieser Prozeß werde zunächst durch Angriffe auf die Philosophie seitens der reaktionären und konservativen Presse angezeigt und verlange schließlich, daß die Philosophie "Zeitungscorrespondent" (S. 184) werde. Eine solche Zeit, die Marx als eine Zeit grundlegender Umgestaltungen der Gesellschaft begriff, war seiner Meinung nach herangereift.

In mehreren Beiträgen untersuchte Marx das Wesen der feudalständischen Vertretung und stieß dabei auf wichtige Fragen der sozialen Gliederung der Gesellschaft. Die Analyse der Debatte des Rheinischen Provinziallandtags über Pressefreiheit förderte bei Marx die Erkenntnis, daß die Zugehörigkeit zum Stand unmittelbar die politische Interessenvertretung, 
die politische Haltung und Gesinnung beeinflußte. In den politischen und sozialen Privilegien des Fürsten- und Ritterstandes suchte Marx die Gründe, warum diese Stände als Gegner der Pressefreiheit auftraten. Diese Abgeordneten verteidigten die „Selbstständigkeit und Freiheit privilegirter Stände" und lehnten die Pressefreiheit unter Berufung auf die „prinzipielle Unfreiheit und Unselbstständigkeit der menschlichen Natur" ab (S. 139). Die Durchleuchtung des Zusammenhangs zwischen sozialer Stellung und politischer Interessenvertretung wurde für Marx' revolutionär-demokratische Entwicklung von außerordentlicher Bedeutung.

Besonderes Interesse verdient die Marxsche Betrachtung der Haltung der Abgeordneten der Städte, die vorwiegend Vertreter der Bourgeoisie waren. Einige von ihnen lehnten die Pressefreiheit ab, einige wollten sie nur mit Einschränkungen akzeptieren. Auf diese Unentschiedenheit und Halbheit wies Marx hin. Diese Haltung brachte er mit der sozialen Stellung und den ökonomischen Forderungen dieser Abgeordneten in Verbindung. Die Ursache für das Verhalten der Vertreter der Städte auf dem Landtag, die Marx als die "liberale Opposition" und deren Haltung er als die „liberale Position" bezeichnete, suchte er darin, daß diese Abgeordneten die „Freiheit der Presse nie als Bedürfniß kennen gelernt" haben (S. 125). Von seinem Interesse für die französische Revolution zeugt in diesem Zusammenhang seine Bemerkung, daß die Opposition der rheinischen Stadtdeputierten auf dem Landtag die „Opposition des Bourgeois, nicht des Citoyen" ist (S. 157). Marx sah von seinem demokratischen Standpunkt aus zwischen der „Opposition des Bourgeois" und dem Auftreten des Fürsten- und Ritterstandes gewisse Gemeinsamkeiten.

Mit dem Artikel "Debatten über das Holzdiebstahlsgesetz" führte Marx im Oktober 1842 die Kritik an den feudalständischen Vertretungen weiter. Er untersuchte hier, wie der Provinziallandtag sich zur preußischen Gesetzgebung verhielt. Dabei bewies Marx, daß die Entscheidungen nicht von allgemeinen Menschenrechten, von der Gleichheit aller Staatsbürger bestimmt wurden, sondern daß die Stände ihre Privilegien, Privat- und Sonderinteressen, geltend machten. Marx schlußfolgerte daraus, „was von einer Ständeversammlung der Sonderinteressen, würde sie einmal ernstlich zur Gesetzgebung berufen, zu erwarten sei" (S. 235). Marx' revolutionär-demokratische Position zeigte sich darin, daß er die feudalständische Verfassung nicht reformieren, sondern abschaffen wollte.

Diese Schlußfolgerung spricht Marx in dem Beitrag „Der Artikel in Nr. 335 und 336 der Augsburger ,Allgemeinen Zeitung' über die ständischen Ausschüsse in Preußen" noch deutlicher aus. Marx' Auseinandersetzung mit den ständischen Ausschüssen stand fast am Ende einer monatelangen öffentlichen Diskussion über die Ausschüsse, die im Sommer 1842 erstmals 
einberufen worden waren und im Oktober und November getagt hatten. Damit wollte die preußische Regierung die Forderung nach einer gesamtstaatlichen Repräsentation befriedigen. Erneut war die liberale und demokratische Opposition entflammt, da statt der geforderten Konstitution die feudalständische Vertretung ausgebaut worden war. In der Antwort auf die Zuspitzung des Gegensatzes zwischen Regierung und Opposition liegen auch vorwiegend die neuen Momente der Marxschen Kritik.

Prinzipieller als bisher führte er den Nachweis, daß die Ständevertretung vorwiegend die Vorrechte des feudalen Grundbesizzes sicherte und immanenter Teil des politischen Systems im preußischen Staat war. Die feudalständische Gliederung der Gesellschaft und der Ausschluß großer Teile des Volkes aus dieser Gliederung seien historisch überlebt, stammten aus dem "Auflösungsprozeß einer vergangenen Zeit" (S. 276) und seien der Gegenwart gewaltsam aufgedrängt worden.

Marx beschäftigte sich auch intensiver als bisher mit der Alternative, daß nur eine Volksvertretung den historischen Anforderungen entsprechen könnte. Er wandte sich offen gegen jene Kompromißvorschläge der liberalen Opposition, wonach die Rechte der Bourgeoisie in den Ständevertretungen erweitert und der Intelligenz der Zugang zu diesen Institutionen verschafft werden sollte. Marx forderte eine Volksrepräsentation, eine wirkliche Interessenvertretung des Volkes. Nicht Privatinteressen, weder das Grundeigentum noch irgendeine andere Form von Eigentum, sondern der freie Mensch sollte in der Volksvertretung repräsentiert werden. Die fehlenden Erkenntnisse über den Klassencharakter des Staates, über die soziale Gliederung der Gesellschaft und die sozialen Triebkräfte der historischen Entwicklung lassen Marx noch an die Illusion glauben, daß die Volksvertretung geistige Mächte verkörpern, daß sie die bewußte Vertretung der Volksintelligenz sein müsse.

Interessant ist in diesem Zusammenhang Marx' Auffassung vom Liberalismus. In der redaktionellen Fußnote „Die , liberale Opposition' in Hannover" erklärte Marx die liberale Verfassung von Hannover, die von der feudalen Reaktion liquidiert worden war, als einen historischen Fortschritt, verdeutlichte aber gleichzeitig, daß diese Verfassung weit von einer Volksvertretung entfernt war. Der "wahre Liberalismus", wie Marx seine demokratische Zielvorstellung hier bezeichnete, hat „eine völlig neue, einem tieferen, durchgebildeteren und freieren Volksbewußtsein entsprechende Staatsform zu erstreben" (S. 250).

Verteidigte Marx einerseits jeden liberalen Fortschritt gegenüber den Angriffen der feudalen Reaktion, machte er andererseits auf Inkonsequenzen der liberalen Opposition aufmerksam und verlangte die volle Verwirklichung der Volksinteressen, so trat er außerdem gegen die radikale 
Kritik der „Freien“ auf. Die „Freien”, eine Gruppe von Junghegelianern um Bruno und Edgar Bauer, wollten mit einer alles negierenden, absoluten Kritik die bestehenden politischen Verhältnisse von Grund auf verändern. Ihre politischen Ziele wurden mehr und mehr radikale Phrasen, die losgelöst von den konkreten politischen und sozialen Verhältnissen, Bedingungen und Voraussetzungen formuliert worden waren, die die realen Möglichkeiten des politischen Kampfes völlig verkannten und zur politischen Isolierung führten. Marx' Stellung zu dieser Gruppe ist vor allem aus seinen Briefen an Arnold Ruge ersichtlich.

Ende November 1842 entsprach Marx einer Bitte Georg Herweghs, dessen Meinung über die „Freien“ in der , Rheinischen Zeitung“ mitzuteilen. Marx ergänzte die Stellungnahme von Herwegh durch die Feststellung: „Der Skandal, die Polissonerie müssen laut und entschlossen in einer Zeit desavouirt werden, die ernste, männliche und gehaltene Charaktere für die Erkämpfung ihrer erhabenen Zwecke verlangt." (S. 372.) Mit der Veröffentlichung des Aufsatzes "Herweghs und Ruges Verhältnis zu den Freien" distanzierte sich die "Rheinische Zeitung" von den „Freien".

$\mathrm{Zu}$ den bedeutendsten politischen Kämpfen in der Rheinprovinz gehörte die Bewegung für die Durchführung einer Kommunalreform, deren Kern die Verteidigung der bürgerlichen Rechtsgleichheit von Stadt und Land war. Die bei der Vorbereitung des Bandes neu entdeckten Artikel von Marx belegen, daß er sich auch zu diesem wichtigen Gegenstand der Auseinandersetzung zwischen der liberalen rheinischen Bourgeoisie und den Volksmassen einerseits und dem Feudaladel und der preußischen Regierung andererseits geäußert hat. Marx verteidigte in den Beiträgen „Die Kommunalreform und die ,Kölnische Zeitung"“ und „Ein Korrespondent der ,Kölnischen Zeitung' und die ,Rheinische Zeitung"“ die Rechtsgleichheit von Stadt und Land, die im Gegensatz zu den übrigen preußischen Provinzen in der Rheinprovinz geltendes Recht war. Unter Berufung auf die Maxime der Französischen Revolution „Gleichheit für alle, für Bürger und Bauer" faßte Marx die Rechtsgleichheit demokratisch.

Marx verteidigte damit ein geltendes Recht gegen Versuche der feudalen Reaktion, dieses Recht zu liquidieren. Indem er die bestehende Gesetzgebung nicht an einem noch zu schaffenden Rechtszustand maß, sondern Übereinstimmung von Recht und realer Wirklichkeit konstatierte, das bestehende Recht als wirkliches, objektives Recht bezeichnete, kamen weitere realistischere Momente in seine Auffassung von Gesetz und Recht. „... so kann das Gesetz nur das ideelle, selbstbewußte Abbild der Wirklichkeit sein, der theoretische verselbstständigte Ausdruck der praktischen Lebensmächte." (S. 259.)

Bei der Verteidigung der Rechtsgleichheit von Stadt und Land bejahte 
Marx erneut die Notwendigkeit einer politischen Gestaltung der Gesellschaft. Indirekt distanzierte er sich sowohl von subjektivistischen Auslegungen, die die Bedürfnisse und Zwecke des einzelnen Individuums zum letzten Prinzip erhoben, als auch von den Gleichheitsauffassungen der utopischen Kommunisten.

Mehrere Beiträge von Marx beschäftigen sich mit dem Charakter der Revision der preußischen Gesetzgebung unter Friedrich Wilhelm IV. und deren ideologischen Grundlagen, von denen eine der bedeutendsten die historische Rechtsschule war. In dem Artikel „Das philosophische Manifest der historischen Rechtsschule" enthüllte Marx den reaktionären Charakter der Ansichten Gustav Hugos, des Begründers dieser Schule. „Ist daher Kant's Philosophie mit Recht als die deutsche Theorie der französischen Revolution zu betrachten, so Hugo's Naturrecht als die deutsche Theorie des französischen ancien régime." (S. 193/194.) Marx deutete damit unmißverständlich an, daß die Vertreter der historischen Rechtsschule mit der Revision der preußischen Gesetzgebung historisch überlebte Zustände restaurieren wollten.

In den Beiträgen „Der Ehescheidungsgesetzentwurf” und "Der Ehescheidungsgesetzentwurf. Kritik der Kritik" analysierte Marx nunmehr unmittelbar einen Wesenszug der Veränderung der preußischen Gesetzgebung. Er wandte sich gegen den Versuch, die Dogmen der protestantischen Kirche unmittelbar zur Grundlage der Gesetzgebung zu machen. Entschieden verurteilte er die Bestrebungen, durch das Gesetz den „,bewußtlosen Gehorsam gegen eine übersittliche und übernatürliche Autorität" zu verlangen (S. 290). Es widerspiegeln sich bereits mannigfaltige politische Erfahrungen, wenn Marx Ende 1842 forderte, daß „das Gesetz der bewußte Ausdruck des Volkswillens" sein muß, „also mit ihm und durch ihn geschaffen" werden muß (S. 289).

In dem Aufsatz "Debatten über das Holzdiebstahlsgesetz" stieß Marx erstmals zu ökonomischen Problemen vor. Marx arbeitete an diesem Artikel zu einer Zeit, da in England Streiks stattgefunden hatten, deren Folgen für Deutschland in der Presse erörtert wurden, und als die allgemeine Pressediskussion über den französischen utopischen Sozialismus und Kommunismus erneut anwuchs. Nicht unbeeinflußt von diesen Diskussionen, beschäftigte sich Marx erstmals mit der Eigentumsfrage und der Lage der besitzlosen Masse.

Ergebnis der Marxschen Analyse der Debatten über das Holzdiebstahlsgesetz war die Erkenntnis, daß das materielle Privatinteresse der Abgeordneten als Eigentümer von Grund und Boden unmittelbar deren politische Entscheidung hinsichtlich der Gesetzgebung bestimmte, daß diese Entscheidung die Rechte und Vorteile der Eigentümer vermehrte und die- 
jenigen der besitzlosen Masse verminderte. Er erkannte, daß die Privateigentümer von Grund und Boden den Staat und seine Rechtsprechung ihren materiellen Bedürfnissen unterordneten. Somit begann Marx sich mit der Rolle des Privateigentums an Grund und Boden auseinanderzusetzen und untersuchte erstmals den Zusammenhang von Gesetz und Eigentum.

Diese Analyse drängte Marx zur ersten Beschäftigung mit dem am meisten ausgebeuteten und unterdrückten Teil des Volkes, mit der besitzlosen, vom Eigentum ausgeschlossenen Masse, die er zunächst als „arme politisch und social besitzlose Menge" (S. 204) charakterisierte. Marx brachte zum Ausdruck, daß „das Dasein der armen Klasse selbst bisher eine bloße Gewohnheit der bürgerlichen Gesellschaft ist, die in dem Kreis der bewußten Staatsgliederung noch keine angemessene Stelle gefunden hat" (S. 209). Die Parteinahme für diesen Teil des Volkes führte ihn zu der Schlußfolgerung, daß eine solche Staatsgliederung zu erstreben sei, in der auch Freiheit und Gleichheit der „,besitzlosen Masse" gesichert werden. Die beginnende Beschäftigung mit der Lage, den Bedürfnissen und Forderungen der besitzlosen Masse bedeutete eine Weiterentwicklung von Marx revolutionär-demokratischem Standpunkt. Gerade in diesen Erkenntnissen liegen Ansatzpunkte für seinen späteren Übergang zum Kommunismus und Materialismus.

Noch suchte er die Lösung in der Verwirklichung eines allgemeinmenschlichen Staatsideals, jedoch führten die neuen Erkenntnisse auch zu neuen Bestimmungen der Aufgaben dieses Vernunftstaates. Er sollte ein Instrument sein, das die Ansprüche und Forderungen des Privateigentums dort unterdrückt und eindämmt, wo sie mit dem Recht auf Freiheit und Gleichheit aller Staatsbürger kollidieren.

Etwa aus der gleichen Zeit, da Marx diese Erkenntnisse gewann, datiert auch seine erste Stellungnahme zum Kommunismus. Die Artikel „Debatten über das Holzdiebstahlsgesetz" und "Der Kommunismus und die Augsburger ,Allgemeine Zeitung " bilden einen Einschnitt in Marx' Entwicklung, der mit dem Beginn seiner Tätigkeit als Redakteur der „Rheinischen Zeitung" zusammenfiel. Werden die sozialen Konflikte, wie sie in England und Frankreich aufgetreten waren, auch in Deutschland ausbrechen? Werden die kommunistischen Ideen auch für Deutschland Bedeutung gewinnen? Das waren Fragen, die Anfang der vierziger Jahre erörtert wurden, die im industriell fortgeschrittensten Teil Preußens, der Rheinprovinz, von besonderer Aktualität waren und mit denen nunmehr auch Marx konfrontiert wurde.

Der Beschäftigung mit dem französischen utopischen Sozialismus und Kommunismus hatte sich Marx offensichtlich im Spätsommer 1842 zugewandt. Äußere Umstände zwangen ihn sehr bald zu einer öffentlichen 
Stellungnahme. Jahre später schrieb er darüber: „Andererseits hatte zu jener Zeit, wo der gute Wille, weiter zu gehen' Sachkenntniß vielfach aufwog, ein schwach philosophisch gefärbtes Echo des französischen Socialismus und Kommunismus sich in der Rheinischen Zeitung hörbar gemacht. Ich erklärte mich gegen diese Stümperei, gestand aber zugleich in einer Kontroverse mit der Allgemeinen Augsburger Zeitung rund heraus, daß meine bisherigen Studien mir nicht erlaubten, irgend ein Urtheil über den Inhalt der französischen Richtungen selbst zu wagen." (Marx: Zur Kritik der Politischen Oekonomie. Erstes Heft. Berlin 1859. Vorwort. S. IV.)

Marx reagierte in den Beiträgen ,Der Kommunismus und die Augsburger ,Allgemeine Zeitung“" und „Zur Polemik über den Kommunismus” auf den französischen utopischen Sozialismus und Kommunismus zurückhaltend. Ausschlaggebend dafür waren die utopischen Züge dieser Lehren, die praktischen Versuche der utopischen Kommunisten und Sozialisten sowie Marx' derzeitige politische und philosophische Ansichten. Mehrmals wies Marxden Vorwurf zurück, die „Rheinische Zeitung" vertrete kommunistische Ideen und verlange deren praktische Verwirklichung. Marx wandte sich jedoch entschieden dagegen, den Kommunismus als bloße Phantasterei abtun zu wollen. Die historische Bedeutung dieser Ideen ahnend, erklärte er, daß „Schriften, wie die von Leroux, Considérant und vor Allen das scharfsinnige Werk Proudhons nicht durch oberflächliche Einfälle des Augenblicks, sondern nur nach lang anhaltenden und tief eingehenden Studien kritisirt werden können" (S. 240).

Marx berührte in seiner Stellungnahme zum Kommunismus wiederum die Existenz einer besitzlosen Masse und begann, die materiellen Interessen dieser besitzlosen Masse in seine Betrachtung einzubeziehen. „Daß der Stand, der heute nichts besitzt, am Reichthum der Mittelklassen Theil zu nehmen verlangt, das ist ein Faktum, welches... in Manchester, Paris und Lyon auf den Straßen Jedem sichtbar umherläuft." (S. 238.) Marx respektierte diese Forderung als eine Tatsache der Zeit, als ein ernstes und wichtiges Problem, dessen Lösung historisch notwendig geworden war.

Die "Rechtfertigung des H-Korrespondenten von der Mosel" veranlaßte Marx erneut, sich mit ökonomischen und sozialen Fragen zu beschäftigen. Wie Marx später des öfteren Engels gegenüber betonte, sei er „,grade durch seine Beschäftigung mit dem Holzdiebstahlsgesetz und mit der Lage der Moselbauern von der bloßen Politik auf ökonomische Verhältnisse verwiesen worden und so zum Sozialismus gekommen" (Engels an Richard Fischer, 15. April 1895).

Die Beschäftigung mit einem seit Jahren andauernden ökonomischen Prozeß, in dessen Ergebnis die kleinen und mittleren Winzer des Moseltales völlig verarmten und massenweise ruiniert wurden, förderte bei Marx 
die Einsicht, daß es sich hier um objektive Vorgänge handelt. „Bei der Untersuchung staatlicher Zustände ist man all zu leicht versucht, die sachliche Natur der Verhältnisse zu übersehen und alles aus dem Willen der handelnden Personen zu erklären. Es gibt aber Verhältnisse, welche sowohl die Handlungen der Privatleute, als der einzelnen Behörden bestimmen und so unabhängig von ihnen sind, als die Methode des Athemholens." (S. 301.)

Da die Moselkorrespondenz nur teilweise überliefert ist, kann nicht eindeutig festgestellt werden, bis zu welchen Konsequenzen Marx die Untersuchung geführt hat. In den beiden vollständig vorliegenden Abschnitten kritisierte Marx, daß die Regierungsbehörden die Ursache für den Verelendungsprozeß der Winzer in Naturereignissen, im Versagen der Winzer oder in Zufällen suchten, aber die eigene Verantwortung ablehnten. Die von der Regierung vorgeschlagenen Maßnahmen wies Marx zurück, da sie den Interessen der Winzer widersprachen. Für ihn stand fest, daß die Moselbauern selbst über keine Mittel verfügten, diesen Prozeß der Verarmung zu verhindern, sondern die äußeren Umstände verändert werden müssen. Auch die Ursache für das Versagen der Staatsbürokratie suchte Marx nicht im Fehlverhalten einzelner Personen, sondern im Wesen der bestehenden preußischen Staatsgesetze und Verwaltungsmaximen. Der Zusammenhang zwischen dem Charakter des preußischen Staates und den sich im Moseltal vollziehenden ökonomischen Prozessen, ein objektiver Zusammenhang, der erstmals in Marx' Blickfeld rückte, war ein wichtiger Ausgangspunkt für seinen Übergang zum Materialismus.

Anfang 1843 begann ein neuer Abschnitt des Kampfes von Marx gegen die preußische Regierung. Die anwachsende Opposition gegen den preuBischen Staat hatte die preußische Regierung Ende 1842 bewogen, rigorose Maßnahmen gegen die oppositionelle Presse durchzuführen. Die erste einschneidende Repressalie war das Verbot der "Leipziger Allgemeinen Zeitung". Zu diesem Ereignis nahm Marx sofort Stellung und verteidigte in einer umfangreichen Zeitungspolemik seinen Standpunkt. Er verurteilte vorbehaltlos und ohne Rücksicht auf taktische Erwägungen das Verbot. Er war auch der erste Publizist, der die eigentlichen Gründe und Absichten der Regierung entlarvte und nachwies, daß dies ein Angriff auf die gesamte fortschrittliche Presse war. Aber er machte auch bewußt, daß der Kampf der Regierung gegen die oppositionelle Presse von der wachsenden Bedeutung der progressiven Kräfte zeugte, ,denn der Kampf gegen ein Dasein ist die erste Form seiner Anerkennung, seiner Wirklichkeit und seiner Macht" (S. 293).

In diesem Zusammenhang kam Marx zum wiederholten Male auf die Bedeutung der fortschrittlichen Presse zurück, begründete am umfassend- 
sten seine Vorstellungen von der gesellschaftlichen Rolle der Presse und prägte den Begriff „Volkspresse“. Marx' revolutionär-demokratischer Standpunkt manifestierte sich in der Forderung, daß die wirkliche Presse ein Sprachrohr der Interessen des Volkes sein und das sich entwickelnde politische Denken des Volkes widerspiegeln muß. Die „Volkspresse“ war für Marx die historische Gestalt des sich entwickelnden „Volksgeistes”. Der Volksgeist, ein von Hegel übernommener Begriff, der in der junghegelianischen Philosophie an Bedeutung gewonnen hatte, war bei Marx Ausdruck der bewußt gewordenen Interessen des Volkes. Zwar noch unter idealistischer Hülle, aber in deutlicher Abgrenzung von subjektiv-idealistischen Geschichtsauffassungen, versuchte Marx erneut, die sich vollziehenden Veränderungen und politischen Ereignisse als einen die Interessen des Volkes zu verwirklichenden objektiven Prozeß zu erfassen. Die Konflikte zwischen den preußischen Staatsinstitutionen und der „Volkspresse" sind für Marx somit Widersprüche zwischen dem preußischen Staat und den objektiven Interessen des Volkes.

Eine Reihe von Dokumenten zeugt von Marx' Kampf gegen die Repressalien der preußischen Regierung. Bemerkenswert ist vor allem, wie Marx die scheinliberalen Zugeständnisse wörtlich auslegte, um dadurch die Ziele und die Existenz der "Rheinischen Zeitung" als gesetzlich zu verteidigen. Sein Kommentar „Kabinettsordre in bezug auf die Tagespresse“, die "Randglossen zu den Anklagen des Ministerialreskripts" und andere Artikel legen davon ein beredtes Zeugnis ab. Diese Taktik brachte Marx bei den radikalen „Freien“ den Vorwurf der Prinzipienlosigkeit ein. Mannigfaltige Erfahrungen hatten Marx jedoch gelehrt, die politischen Kräfte real einzuschätzen und innerhalb der bestehenden Gesetzlichkeit alle Möglichkeiten des revolutionären Kampfes zu nutzen. Dies wurde fortan ein Wesenszug des politischen Kampfes von Marx.

Zu Marx' Erfahrungen aus jener Zeit gehörte es auch, Entscheidungen des preußischen Staates nicht kampflos und unwidersprochen hinzunehmen. Das bewies er vor allem durch seine Reaktion auf das am 20. Januar 1843 von der preußischen Regierung erlassene Verbot der ,"Rheinischen Zeitung". Marx war sich bewußt, daß zwischen den Interessen der preußischen Regierung und den Zielen der „Rheinischen Zeitung” ein unüberbrückbarer Gegensatz bestand und dies die eigentliche Ursache für das Verbot der "Rheinischen Zeitung" war. Er schätzte deshalb die Chancen für eine weitere Existenz des Blattes sehr real ein. Dies hinderte ihn jedoch nicht, einen energischen Kampf gegen den Regierungserlaß zu führen. Er verteidigte die Haltung der ",Rheinischen Zeitung", nutzte geschickt die mannigfaltige Opposition im preußischen Staat und die Differenzen innerhalb der herrschenden Klasse aus. 
Neue Aufschlüsse über Marx' Rolle bei der Verteidigung der „,Rheinischen Zeitung" vermittelt die "Denkschrift betreffend die Unterdrückung der "Rheinischen Zeitung"“, die, wie im vorliegenden Band erstmals nachgewiesen wird, mit hoher Wahrscheinlichkeit von Marx verfaßt worden ist. Ist der dritte Abschnitt dieser Denkschrift eine vermutlich von Marx überarbeitete Fassung der "Randglossen", so erbringen die beiden ersten Abschnitte neue Gesichtspunkte über Marx' Kampf gegen die preußische Regierung. Marx konfrontierte die Verbotsmotive mit der bestehenden preußischen Pressegesetzgebung, spürte jeden Widerspruch auf und führte so den Nachweis, daß die Maßnahmen der Regierung sogar auf der Basis der bestehenden Gesetzgebung als Willkürakt zu werten waren.

Ergänzendes Material über Marx' Kampf gegen das Verbot der „Rheinischen Zeitung" bietet der Teil Dokumente im Anhang. Von Interesse ist vor allem Marx' Auftreten auf der außerordentlichen Generalversammlung der Aktionäre der Rheinischen Zeitungsgesellschaft.

Ein Grundzug der publizistischen Arbeiten von Marx ist die Auseinandersetzung mit der herrschenden Ideologie. Besonders interessant sind die Zeitungspolemiken, die Marx teilweise selbst begann, die aber auch durch Angriffe auf seine Beiträge verursacht worden waren. Charakteristisch für Marx war, daß die Parteinahme für die Interessen des Volkes und die Auseinandersetzung mit den reaktionären, die feudalen Verhältnisse und die Politik des preußischen Staates rechtfertigenden Anschauungen Hand in Hand gingen. Hierin zeigte sich bereits im Keim ein Wesensmerkmal der Entstehung und Entwicklung der proletarischen Weltanschauung, die sich nur im Kampf gegen feudale, bürgerliche und kleinbürgerliche Theorien herausbilden konnte.

Gleichzeitig erkennt man bereits in diesen ersten publizistischen Beiträgen die individuelle Stärke von Marx, seine außerordentliche Fähigkeit, eine parteiliche, scharfe und treffende Polemik zu führen. Seine Kunst der Polemik trug nicht unwesentlich dazu bei, daß bereits die Aufsätze des revolutionären Demokraten Marx eine große Überzeugungskraft ausstrahlten.

Zu den umfangreichen Aufgaben, die Marx als Redakteur zu bewältigen hatte, gehörte auch der redaktionelle Kommentar in Form von Fußnoten oder Bemerkungen. Nur einige dieser Beiträge konnten mit Sicherheit Marx zugeschrieben werden, der größere Teil ist unter Dubiosa aufgenommen worden. Der Teil Dubiosa enthält außerdem einige Leitartikel. Diese Dokumente beinhalten vielfältige politische Probleme. So ergänzt der Artikel „Die neue Zensurinstruktion” die Kritik der preußischen Zensurgesetzgebung und vermittelt interessante Parallelen zu den ,Bemerkungen über die neueste preußische Zensurinstruktion". Die Fußnote "Über 
Geschwornengerichte" enthält eine knappe Charakteristik dieser durch die französische bürgerliche Gesetzgebung in der Rheinprovinz eingeführten Institution und weist auf Vorzüge sowie Mängel dieser Gerichte hin. Ebenfalls in einer Fußnote wird Proudhon als der "konsequenteste, scharfsinnigste socialistische Schriftsteller" (S. 417) bezeichnet.

Mit der „Erklärung" vom 17. März 1843 gab Marx seinen Austritt aus der Redaktion der "Rheinischen Zeitung" bekannt. Wegen der rigorosen Zensur, aber auch wegen der Meinungsverschiedenheiten zwischen ihm und den Geranten hinsichtlich möglicher Zugeständnisse schied Marx schon einige Tage vor dem Erscheinen der letzten Nummer der Zeitung aus.

Damit endete ein bedeutungsvoller Abschnitt in Marx politischer und philosophischer Entwicklung. Er selbst faßte Jahre später zusammen: „Im Jahr 1842-43, als Redakteur der ,Rheinischen Zeitung', kam ich zuerst in die Verlegenheit, über sogenannte materielle Interessen mitsprechen zu müssen. Die Verhandlungen des Rheinischen Landtags über Holzdiebstahl und Parzellirung des Grundeigenthums, die amtliche Polemik, die Herr von Schaper, damals Oberpräsident der Rheinprovinz, mit der Rheinischen Zeitung über die Zustände der Moselbauern eröffnete, Debatten endlich über Freihandel und Schutzzoll, gaben die ersten Anlässe zu meiner Beschäftigung mit ökonomischen Fragen." (Marx: Zur Kritik der Politischen Oekonomie. Erstes Heft. Berlin 1859. Vorwort. S. IV.)

In diesen Monaten nahm Marx Partei für die „besitzlose Masse”, verteidigte ihre politische Forderung, gleichberechtigte Staatsbürger zu werden, und anerkannte ihre materielle Forderung, am Reichtum der Bourgeoisie teilnehmen zu wollen. Marx stieß zu wesentlichen Erkenntnissen über die soziale Gliederung der Gesellschaft und den Zusammenhang von Eigentum und politischer Interessenvertretung vor. Er begann, sich mit dem französischen Sozialismus und Kommunismus auseinanderzusetzen. Sein revolutionär-demokratischer Standpunkt wurde immer bestimmter und konsequenter.

Die Auseinandersetzung mit den wichtigsten politischen Forderungen der bürgerlichen und demokratischen Oppositionsbewegung erbrachte neue Einsichten und erste Erfahrungen im politischen Kampf. Die direkte Konfrontation mit der Politik des preußischen Staates, seinen Institutionen, seiner Gesetzgebung und seinen Verwaltungsmaximen ergänzte Marx' politische Erfahrungen und Erkenntnisse über den Charakter des politischen Systems in Preußen.

Das von Marx geforderte und praktizierte Bündnis von Philosophie und Politik, die Darlegung und Entwicklung der Philosophie innerhalb der Analyse konkreter politischer Verhältnisse beschleunigte den Erkenntnisprozeß, verstärkte die revolutionären und realistischen Züge in Marx' 
philosophischen Ansichten. Marx führte die kritische Auseinandersetzung innerhalb des Junghegelianismus weiter und trieb selbst dessen Differenzierungsprozeß voran. Bedeutungsvoll für seine Entwicklung war die Beschäftigung mit Feuerbach, die Distanzierung von den subjektiv-idealistischen Auffassungen der "Freien" und die Diskussion mit Ruge. Noch war Marx' Weltanschauung wesentlich an Hegels objektiv-idealistischer Geschichtsdialektik orientiert, die realistischen, die Wirklichkeit immer tiefer erfassenden Züge verstärkten sich aber mehr und mehr.

Lenin gelangte vor allem im Hinblick auf die neuen Ansatzpunkte von Marx' politischer und philosophischer Entwicklung zu dem Urteil, daß sich in den Artikeln der ",Rheinischen Zeitung" "schon Anzeichen für Marx' Übergang vom Idealismus zum Materialismus und vom revolutionären Demokratismus zum Kommunismus" finden (W.I. Lenin: Karl Marx. In: Werke. Bd. 21. Berlin 1974. S. 69). Einige Monate später vollzog Marx den Übergang zum Materialismus und Kommunismus und formulierte die Erkenntnis von der historischen Rolle des Proletariats. 